\title{
Relation between Self Esteem with Marital Satisfaction of Employed Women in Payam-e-Noor University
}

\author{
Mohammad Ehsan Taghizadeh \\ Doctorate of Education Psychology, Department of Psychology \\ Payame Noor University (PNU), P.O. Box 19395 - 3697, Tehran, Iran
}

\section{Elham Kalhori}

Master of Science of General psychology, Department of Psychology, Payame Noor University (PNU) P.O. Box 19395 - 3697, Tehran, Iran; Email: k_elham63@yahoo.com

\section{Doi:10.5901/mjss.2015.v6n6s6p41}

\section{Abstract}

\begin{abstract}
Marital adjustment affects many aspects of people's individual and social life. Self-esteem is one of the factors that may affect marital satisfaction. This study aimed to investigate the relationship between self-esteem and marital satisfaction in women employed in Payame Noor University of Shahre Rey in 2014. This is a descriptive-correlational study of cross-sectional type. Its population included 94 people. Inclusion criteria were: Iranian nationality, married with at least one year of married life, etc., and the exclusion criteria included: unwillingness to continue cooperation and respondents who got a score of 4 out of 8 item Cooper smith Self-Esteem Inventory. Four questionnaires were used for data collection: Personal information of the samples, Coopersmith Self-Esteem Inventory, ENRICH's marital satisfaction and Female Sexual Function Index (FSFI), and sexual satisfaction Inventory. Results show that the majority of participants (55.6\%) had relative and moderate marital satisfaction. The majority of the samples (92 \%) had high self-esteem. There was a significant relationship between marital satisfaction, economic status and sexual satisfaction. The results of the logistic regression analysis showed that probability of marital dissatisfaction in individual with low self-esteem is 9 times higher than normal people, 5 times among those with low sexual satisfaction, and 3 times among people dealing with bad economic condition. Results show that there is a significant relation between marital dissatisfaction and self-esteem, sexual satisfaction and economic status.
\end{abstract}

Keywords: Self -esteem, marital satisfaction, sexual satisfaction, economic status.

\section{Introduction}

Marriage is considered in public thought of society and scientific and academic researches as base of shaping family institution and the most important event in personal life. Marriage is an important social and legal institution that protects marital stable relations by preparation special collection of rights, points, commitments, responsibilities and anticipations and causes survival and continuation of family institution and social structure (Zandipour \& Momeni, 2011). Marriage causes calmness and recreation, personal and social development, supply sexual needs, generation survival and supply mental needs which its outcomes are personal and social health. Lacking satisfying accurate and on time of these needs, damage non compensable losses to person and social. Marital satisfaction is subjective feeling from satisfaction, peacefully, and pleasure experienced by man and woman when all positive aspects of their life are considered (Rubel, 2004). This variable is supposed as spectra from much satisfaction or much dissatisfaction (Shahi baravati, 2001).

Results of research showed that one fourth of women having higher education and one third from women having diploma degree had serious till much serious marriage status and need serious couple therapy (MSM, 2004). In majority of reports, as for differences, it was shown that scale of prevalent of incompatibility is increasing as different cases (Wagheiy, Miri \& Ghasemipour, 2010).

Marital adjustment affects on much aspects of personal and social life of humans. Satisfied marital relations are infrastructure of good performance of family and cause growth of capability and compatibility between children (Cumming SM ORW, 1997); restore educational status (Cumming SM ORW, 1997) and low inclination into alcohol or drug (Amato, 1993). Also, results of studies showed that the married persons who have stable life and satisfy their life more, have longer age (Coombs, 1991), health and suitable nutrition ((Waite, 1996), (ND G, 1996)), it is possible to save from cancer more (Coombs, 1991) and it is little to expose in depression and psychological difficulties ((Waite, 1996), (Demo \& Acock, 
1996)). Marital satisfaction affects on satisfaction from life and income, studying success, and satisfaction from occupation of couples. In other side, incompatibility in relations between couples causes distortion in social relation, inclination into social deviances and wane of cultural values between wives and spouses (Zandipour \& Momeni, 2011).

During shared life, different variables affect on manner of couples relations with each other like gender, age, marriage age, time of marriage, income, economic pressures, studying suitability, social status, employment, number of children, health of children, relatives and acquaintances, religious beliefs, mental status, disease and sexual satisfaction ((Zandipour \& Momeni, 2011), (Banaian \& Parvin, 2006), (Song, Bergen \& Schumm, 1995)). About effectiveness of family marriage on marriage satisfaction, there is difference ((Sadegh, Askari, Maruzi, Shams, Tahmasbi \& Paper), (Flsloglu, 2001)). One of the factors which affect on marriage satisfaction is self esteem.

Self esteem is as factor that influences on comprehension, interpretation and emotional reactions of person and can be determinant on scale of de stress of events. Self esteem is like as collection of outcomes and beliefs which has been stated in relation between person and his outer world. In other word, it is citation of confirmation or lacking confirmation of person into expectancy of success, accept and react into personal determinants (Akram, 2000). Based on Mazlo point of view, each person has needs in order to reach in suitable level of health which shall be satisfied and self esteem is one of the basic human needs which locates in emotional dimension (Taylor, 2008). When person had positive estimation from his characters, have high self esteem and when the result is negative, self esteem is low. It shall be considered that self esteem is important factor for progressing and success of persons in all works and marital life and environment plays effective role in shaping it (Ravanbakhs). There is unified and coordination between alarm and passions on person who have high selfesteem (A P, 2009). But persons with low self esteem repress their ability for citation of sexual and marital inclination (MC Kay M FP, 2008). It was seen in some of studies that there is direct and positive relation between selfesteem and marital satisfaction ((Pourdehghan \& Mahmmudnia, 2008), (Masoud, 2001)). In current complicated world, satisfaction from life is regarded as important category of life. Marital satisfaction is milestone of strong family that in its hot focus, the humans grown and can change their destiny and society in which live. Although, in our country, severity of problems is not as like as other countries because of religious belief, ethical values and cultural texture, thus, it cannot be ignored different dissatisfaction and problems in this field. Since marital satisfaction is different in work environment and different cities and cultures, in this research, we discuss relation between self esteem to marital satisfaction in employed women at Payam-e-Noor University in Tehran.

\section{Methodology}

The present research is correlation- descriptive one from cross sectional type which aimed to discuss relationship between self esteem to martial satisfaction of women who employed in Payam-e-Noor University of Shahr-e-Rey Branch. From said society, a sample with volume 94 people were selected as sampling and estimated. The inclusion scales are: Iranian nationality, married and having shared life with spouse, at last one year since marriage, lacking abortion or child birth, lacking expose to mental, bodily, gynecologic disorders or other body orgasms which are known and exclusive scales included: unwillingness to continue cooperation and respondents who got a score of 4 out of 8 item Cooper smith Self-Esteem Inventory. Four questionnaires were used for data collection: Personal information of the samples, Cooper smith Self-Esteem Inventory, ENRICH's marital satisfaction and Female Sexual Function Index (FSFI), and sexual satisfaction Inventory. In order to determine validity of questionnaire, demographic of validity with amendment of 10 professors of university has been used and its confidence is estimated by reexamination method. Cooper smith self esteem questionnaire has 58 articles which 50 articles devote to 4 general subscales of self esteem, social self esteem, family self esteem and self esteem in work environment and 8 articles devote to liar estimation. Method for pointing to this test is as zero and one that means yes answer is true about articles 2-4-5-10-14-18-19-21-23-28-29-30-32-36-45-47-57 for point one and answer no devotes to zero point and other questions are pointed as converse. In this test, minimum point is zero and maximum will be 50 and if the respondent gets 4 point from 8 questions, it means that validity of test is low and the testable tried to present himself better than before. This test is valid and its validity and credit was discussed in different studies (Akram, 2000). The original version of marital satisfaction of Enrich has 115 questions. As for longer questions of scale, a form with 47 questions was made and used in this research. In this form, 5 options devoted for each question.

The options are completely agree, agree, don't theory, disagree and completely disagree. The marking of questions are as 4,3,2,1 and 5. Maximum point for testable equals to 235 and higher point shows marital satisfaction. Alpha coefficient for credit of form with 47 questions is 0/95 (Gahfahom, 2008). FSFI questionnaire which estimates sexual satisfaction consists of 19 questions of 5 options which estimate sexual willingness, stimulation, orgasm, and sexual pain, vaginal wet and sexual satisfaction. In this questionnaire, each questionnaire has 5 points in which its factor 
is multiplied and total point will be obtained with summation of points of six domains. Validity of questionnaire was determined with using research of Mohammmadi and et al (A P, 2009), that has high validity as for meaningful level of total points and scale of credit and of scales and subscales with calculation of alpha kronbach is $70 \%$ in all people.

After obtaining confirmation of ethical committee and written consent from employees, a 4 parts questionnaire was given to each and after completing it, the questionnaires are collected. Descriptive statistics has been used for describe demographic specifications of health of sample. In order to discuss factors that have capability for predication of marital satisfaction, logistic regression analysis has been used and in order to compare different factors in different group, Man Whitney Test, Fisher and K Test have been used. All statistical analysis was performed with using SPSS version 20 and their $\mathrm{p}$ was considered lower than 0/5.

\section{Findings}

Based on findings of this study, average age of the samples was 30/32+-5/43 and average age of their spouses was $37 / 52+-7 / 21$. The highest educational level of testable (32\%) and their spouses (30\%) was master. Average of duration of marriage $7 / 12+-5 / 5$ years. Method for prevention from pregnancy was natural in majority of samples (63\%). Average of number of abortions 0/41+-0/63 and number of pregnancy was 1/73+-1/18. Average of child birth was 1/5+-0/73 and average of number of children was 1/5+-0/73. All samples have health children and from religious point of view, there were in one level and $5 \%$ had family marriage. $56 / 17 \%$ had disorder in sexual satisfaction. Based on results, majority of majority of persons (55/6\%) had relative satisfaction from their marital satisfaction. Also, majority of samples (92\%) had high self esteem and $8 \%$ had low selfesteem. Man Whitney test showed that there is significant relation between disorders of marital satisfaction with economic status (scale of monthly income, home infrastructure, and possession of residential unit) ( $p=0 / 002)$ and Fisher perfect test showed that there is significant relation between self esteem and sexual satisfaction with marital satisfaction. ( $\mathrm{P} \leq 0 / 001)$. Results of logistic regression analysis with confidence distance $95 \%$ showed that chance of occurrence marital satisfaction in persons who have low self esteem is 9 than persons with persons with high self esteem. Also, chance of occurrence for disorder of marital satisfaction is 5 and in persons with worst economic status 3 than other persons. (Table 1)

Table 1. Results of logistic regression about effect some of variables on marital satisfaction

\begin{tabular}{|l|c|c|c|c|}
\hline Variable & Deviance & $\mathrm{P}$ & Rate of chance & Confidence distance 95 \\
\hline Self esteem & $1 / 34$ & $0 / 01$ & $9 / 32$ & $(1 / 84-162 / 49)$ \\
\hline Sexual satisfaction & $0 / 86$ & $0 / 05$ & $5 / 17$ & $(1 / 98-31 / 83)$ \\
\hline Economic status & $0 / 62$ & $0 / 06$ & $3 / 21$ & $(0 / 94-137 / 23)$ \\
\hline
\end{tabular}

\section{Discussion and Concluding}

The results of study showed that majority of persons had relative marital satisfaction and high self esteem. There is significant relation between marital satisfaction to self esteem, sexual satisfaction and economic status, and chance of occurrence in persons with low self esteem is 9 and in persons with sexual satisfaction is 5 and in persons with economic status is 3 . In this study, majority of persons had relative satisfaction which conforms to other researches in Iran ((Zandipour \& Momeni, 2011), (Wagheiy, Miri \& Ghasemipour, 2010), (Banaian, 2006)).

We saw that there is significant relation between self esteem and marital satisfaction and in persons with low self esteem it is 9 than other persons with high self esteem and there is chance of occurrence marital satisfaction. Ourt and et al, 2012, Nouripor and et al, 2015 obtained similar results ((Pourdehghan \& Mahmmudnia, 2008), (Rahmani, Khoei \& Sadeghi Gholi, 2008), (Guob, 2005)). We can say that self esteem is a factor for developing and success of people in marital satisfaction and the environment plays effective role in shaping self esteem. Marital satisfaction is derived from reward behaviors and resulted from high self esteem. From Elis point of view, marital satisfaction is subjective feelings from satisfaction, pleasure experienced by man and woman who consider all aspects of their marriage. Satisfaction is insight variable and thus it is regarded as personal specification of man and woman. Importance of self esteem is derived from close relationship with compromised growth and personality performance (Litzinger \& Gordon, 2005). Also, it is recognized that scale of self esteem is pertinent to positive insight and wife and husband sympathy (Pourdehghan \& Mahmmudnia, 2008).

The findings of this research is certified that sexual satisfaction is pertinent to marital satisfaction as significantly and scale of lacking satisfaction from marital satisfaction in persons with low sexual satisfaction is 5 more than other 
persons. Many studies were performed in this field which conforms to our results ((Bakhshayesh, 2010), (Brezsnyak \& Whisman, 2004), (Nichols, 2005), (J SW, 2000), (Byers, 2005), (Nakonezny, 1995), (Atari, Fard \& Honarmand, 2006), (Hassan, 2003)). in these researches, sexual satisfaction is effective factor in marital relations and sexual activity is so important in which lacking sexual activity can be derived from other problems on marriage.

As displayed in study, relationship between economic status and marital satisfaction is positive and lower economic status increases marital dissatisfaction to 3 . These findings conform to findings of other researchers (Atari, Fard \& Honarmand, 2006). Lacking bodily security causes instability of life, dissatisfaction from marriage and life. The persons who are regarded as poverty and without money have stimulated behaviors. Economic problems influences quality and stability of marriage life between couples by make emotional heartsick and negative patterns between couples (Byers, 2005).

Self esteem causes person feels he is valuable member of family and has respect. As for importance of self esteem and its relationship with human behaviors and actions like in family dimension and in other side role of self esteem on marital satisfaction, it is suggested that this case will be considered in family, schools, center of higher education and in mass media and provide suitable bed for it by increase public awareness to importance of self esteem, educate life skills and methods for reach in it.

Also, necessity of having ability in good sexual relationship is to have skills that are educable and as many of couples think, it is not far from access. We can increase marital adjustment by increment couples skills and based on it, suggestion of this research is about education and family consulting specially about educates sexual problems to couples in order to increase marital satisfaction and stability and persistence of families.

\section{References}

Zandipour.T, Momeni. JM. A Study on the relationship Between Marital satisfaction and Job Satisfaction Among Employees of Sewage Water Company in Tehran. Quarterly Journal of Career \& Organizational Counseling 2011;3(7):113-29.

Rubel, BS. Exploing contribution of relational self to men's identity achievement: trinttidentity achievement: trintty western university; 2004.

A. S. Mental health. Shahi baravati H. (Persian translator) 1st ed. Tehran; Ravan Publication 2001:22-3.

M SM. A survey on the marriage satisfaction of educated women. Ministry of sciences, researches and technology: The office of social and cultural studies and planning. 2004;2004(4):70-5. [Persian]

Wagheiy Y, Miri M, Ghasemipour M. A survey about effective factors on the marital satisfaction in employees of two Birjand universities. Journal of Birjand University of Medical Sciences. 2010;16(4):43-50.

Cumming SM ORW. Fathers in family context: effects of marital Quality on child adjustment in the role of the father in child Development. 1st. ed .New York: John Wiley and sons; 1997. pp: 863-891.

Westerman MA, La Luz EJ. Marital adjustment and children's academic achievement. Merrill-Palmer Quarterly (1982-). 1995:453-70.

Amato PR. Children's adjustment to divorce: Theories, hypotheses, and empirical support. Journal of Marriage and the Family. 1993:2338.

Coombs RH. Marital status and personal well-being: A literature review. Family relations. 1991:97-102.

Waite L. Why marriage matters strengthening marriage round table. Washington DC.1997

ND G. The Text book story of American marriages and families. New York: Institute for American Values;1996.

Demo DH, Acock AC. Singlehood, Marriage, and Remarriage The Effects of Family Structure and Family Relationships on Mothers' Well-Being. Journal of Family Issues. 1996;17(3):388-407.

Banaian S, Parvin N. The Investigation of the Relationship Between Mental Health Condition and Martital Satisfaction. Scientific Journal of Hamadan Nursing \& Midwifery Faculty. 2006;14(2):52-62.

Malekpur M JN. A survey on the relation between the stress of parents (having Mental Retarded Child) with the intense of Retardation, children sex and age, social-economics level and education of parents. Journal of Pajuheshhaye Tarbiyati va Ravenshenakhti . .56-37:(3)1;1997. [Persian]

Floyd FJ GL, Costigan CL. Marriage and the parenting alliance: longitudinal prediction of change in parenting perceptions and behaviors. Child Dev. 1998;69(5):1461-79.

Robila M, Krishnakumar A. Effects of economic pressure on marital conflict in Romania. Journal of Family Psychology. 2005;19(2):246.

Song JA, Bergen MB, Schumm WR. Sexual satisfaction among Korean-American couples in the midwestern United States. Journal of sex \& marital therapy. 1995;21(3):147-58.

Sadegh. ML, Askari. F, Maruzi. P, Shams. H, Tahmasbi. S. Paper: Comparison of marriage satisfaction in housewives and employed women and their husbands in Gonabad, IRAN.

Flsloglu H. Consanguineous marriage and marital adjustment in Turkey. The Family Journal. 2001;9(2):215-22.

Akram D., Discussion relationship between self esteem, skill and mental health between students of first grade of high school of Tehran, Master Degree Course Thesis, Management and Programming Faculty, Tarbiyat Modarres University, 2000

Taylor C. Fundamental of Nursing: Translate by Mahdaviz. Tehran Boshra. 2008.

Ravanbakhs A, Discussion Relationship with self esteems and stress between Teachers of Kermanshah, Master Degree Course Thesis, 
Management and Programming Faculty, Ta A P. How to develop self confidence.Tranlate by Azad Hossien. second ed. Tehran Besat 2009.

MC Kay M FP. Self - esteem. Translate by shararai mehrnaz. 1th ed. Tehran. Asim 2008.

M. Pourdehghan SM, A.R. Mahmmudnia. Relation between Self - Esteem and Marital Satisfaction among Guidance School Teachers. Journal of Applied Psychology. 2008; 4(8):701-12.

Tarbiyat Modarres University, 2000

Masoud T, Discussion and Compare Illegal Beliefs and Marital Satisfaction of employed couples, Master Degree Course Thesis, Psychology and Educational Sciences University, Alzahra University, 2001

L. Gahfahom, Determine Effectiveness of educate change life style as group on increment marital satisfaction, Psychological Studies magazine of Alzahra University, 2008, 3, 4

A P. How to develop self confidence. Tranlate by Azad Hossien. second ed. Tehran Besat 2009.

MC Kay M FP. Self - esteem. Translate by shararai mehrnaz. 1th ed. Tehran. Asim 2008.

M. Pourdehghan SM, A.R. Mahmmudnia. Relation between Self - Esteem and Marital Satisfaction among Guidance School Teachers. Journal of Applied Psychology. 2008; 4(8):701-12.

Rahmani, Khoei, Sadeghi Gholi, Relationship of sexual satisfactrion and satisfaction from life, Iran Nursing Magazine, Guob, Huang J. Marital and sexual satisfaction in Chinese families: Exploring the moderating effects. Journal of sex \& marital therapy. 2005;31(1):21-9.

Litzinger S, Gordon KC. Exploring relationships among communication, sexual satisfaction, and marital satisfaction. Journal of sex \& marital therapy. 2005;31(5):409-24.

A.R. Bakhshayesh(PhD) MMB. the relationship between sexual satisfaction, general health and marital satisfaction in couples. Journal of Applied Psychology. 2010 4(12):73-85.

Brezsnyak M, \& Whisman, M. Sexual desire and relationship functioning; It's effect of marital satisfaction and power. Journal of Sex and Marital Therapy. 2004;30(3):199-217.

Nichols M. Concurrent discriminant validity of the Kansas marital satisfaction scale. J Marriage Fam. 2005;48(2):381-7.

J SW. Relationship between lifestyle and factors affecting sexual life. Journal of Sexual and Relationship Therapy. 2000;15(2 ):367-80.

Byers ES. Relationship satisfaction and sexual satisfaction: A longitudinal study of individuals in long-term relationships. Journal of sex research. 2005;42(2):113-8.

Nakonezny PA, Shull RD, Rodgers JL. The effect of no-fault divorce law on the divorce rate across the 50 states and its relation to income, education, and religiosity. Journal of Marriage and the Family. 1995:477-88.

Atari $\mathrm{Y}$, Fard $\mathrm{A}$, Honarmand $\mathrm{M}$. An investigation of relationships between personality characteristics and familypersonal factors and marital satisfaction in administrative office personnel in Ahvaz. J Educ psychol. 2006;13:81-108.

Hassan A. Discussion effect of personality characters on marital satisfaction of couples on Damghan, Master Degree Thesis, Tabriz Univeristy, 2003. 